\title{
Elin Beate Tobiassen, La Relation écriture-lecture. Cheminements contemporains. Éric Chevillard, Pierre Michon, Christian Gailly, Hélène Lenoir
}

\section{Gianmaria Finardi}

\author{
(2) OpenEdition \\ Journals \\ Edizione digitale \\ URL: http://journals.openedition.org/studifrancesi/5782 \\ DOI: $10.4000 /$ studifrancesi.5782 \\ ISSN: 2421-5856 \\ Editore \\ Rosenberg \& Sellier
}

\section{Edizione cartacea}

Data di pubblicazione: 1 septembre 2011

Paginazione: 461

ISSN: 0039-2944

\section{Notizia bibliografica digitale}

Gianmaria Finardi, «Elin Beate Tobiassen, La Relation écriture-lecture. Cheminements contemporains. Éric Chevillard, Pierre Michon, Christian Gailly, Hélène Lenoir», Studi Francesi [Online], 164 (LV | II) | 2011, online dal 30 novembre 2015, consultato il 13 janvier 2021. URL: http://journals.openedition.org/ studifrancesi/5782 ; DOI: https://doi.org/10.4000/studifrancesi.5782

Questo documento è stato generato automaticamente il 13 janvier 2021.

\section{c) (†) $\odot$}

Studi Francesi è distribuita con Licenza Creative Commons Attribuzione - Non commerciale - Non opere derivate 4.0 Internazionale. 


\title{
Elin Beate Tobiassen, La Relation écriture-lecture. Cheminements contemporains. Éric Chevillard, Pierre Michon, Christian Gailly, Hélène Lenoir
}

\author{
Gianmaria Finardi
}

\section{NOTIZIA}

Elin Beate TOBIASSEN, La Relation écriture-lecture. Cheminements contemporains. Éric Chevillard, Pierre Michon, Christian Gailly, Hélène Lenoir, Paris, L'Harmattan, 2009 («Critiques littéraires»), $184 \mathrm{pp}$.

1 In questa raccolta di saggi E. B. Tobiassen si propone di auscultare quattro voci della narrativa francese contemporanea, selezionate in quanto espressioni differenti di una medesima tematica: il rapporto tra scrittura e lettura.

2 Nei due interventi introduttivi, che hanno per oggetto Le Vaillant petit tailleur di Chevillard, la relazione tra atto di scrittura e atto di lettura prende la controversa forma della riscrittura di un testo preesistente. Come emerge sin dall'osservazione dell'incipit, infatti, la ripresa della celebre fiaba dei Grimm si inscrive nel solco di una sostanziale ambiguità, ponendosi ora come rifacimento ironico, ora come espressione volutamente malcelata dell'interiorità dell'autore. Mentre suggerisce queste interpretazioni alternative, il testo autorizza il lettore a percorrere due differenti strade: una univoca, che gli impone di seguire faticosamente il senso che il testo ancora consegna a chi legge nonostante i numerosi dispositivi di depistaggio, l'altra ramificata, giacché lo lascia libero di sfruttare le molteplici potenzialità della scrittura.

Nel caso di Vies minuscules di Michon, oggetto del terzo contributo, la tematica in questione sconfina nella dimensione extra-finzionale delle vite lacunose che un narratore tramanda, dopo averle a sua volta sentite raccontare dalla nonna Élise. 
Risultando inestricabilmente intrecciate al racconto, tali minuscole esistenze sono indicative di una duplice postura autoriale. Si percepisce da un lato una certa sfiducia nelle effettive possibilità di raccontare le biografie, ineluttabilmente risucchiate nella finzione che le veicola. Dall'altro, l'esempio positivo originariamente offerto da Élise dimostra una fede residua nella forza della narrazione, ancora in grado di penetrare il reale e di restituire quelle vite altrimenti destinate all'oblio.

4 I problemi legati al blocco creativo divengono l'oggetto principale della sezione dedicata alle opere dell'esordio letterario di Gailly, Dit-il e $K$ 622. Entrambi i testi portano i segni del passaggio da un'espressione artistica ad un'altra intrapreso negli anni ' 80 da Christian Gailly, che smette i panni del sassofonista per indossare quelli dello scrittore. La medesima tensione verso il bello, valore assoluto cui aspira l'autore, si traduce diversamente nei due testi: nel primo, legato alle eredità sperimentali della narrativa francese, prevale una tensione nichilista. Il secondo, invece, pare sintomatico di una certa resistenza alla tentazione del mutismo; in $K 622$, come segnala il riferimento all'opera di Mozart, il ritorno alla narrazione fa assumere al testo i connotati di un fatto musicale, da ascoltare forse prima ancora che da leggere.

5 Nel capitolo conclusivo, teso ad esaminare la relazione tra La Brisure di Hélène Lenoir e Tropismes di Nathalie Sarraute, si sviluppa l'aspetto squisitamente intertestuale della dialettica tra scrittura e lettura. Osservate in quanto attualizzazioni delle potenzialità insite nell'ipotesto, del resto, le ambiziose riprese di Lenoir suggeriscono l'idea già espressa da Genette di una letteratura intesa come sistema filiale tra testi, dove «l'écriture ne cesse de se lire» e «la lecture ne cesse de s'écrire» (citato a p. 14). 